\title{
Pemberdayaan Masyarakat Korban Tsunami Selat Sunda Kampung Nelayan Teluk Labuan Banten
}

\author{
Sutarman $^{1}$, Yuyun Yuniarsih ${ }^{2}$, Maria Grace Herlina ${ }^{3}$ \\ STMIK Triguna Utama ${ }^{1}$, Universitas Sangga Buana USB Bandung ${ }^{2}$, Universitas Bina \\ Nusantara ${ }^{3}$ \\ Email: 1amrisutarman@yahoo.com, 2yuyunyuniarsih49@gmail.com, \\ 3mgrace.herlina@gmail.com
}

\begin{abstract}
The tsunami that occurred in the Sunda Strait was a big wave in the harbor between the two islands namely the displacement of water bodies caused by changes in sea level vertically came suddenly. Changes in sea surface structure can be caused by earthquakes that are centered under the sea, underwater volcanic eruptions, underwater landslides, and the impact of meteors at sea. The tsunami waves hit tens of kilometers off the coast, damage and casualties caused by the tsunami due to the impact of water and material carried by the tsunami wave currents. In its implementation of community service in the form of preparations for the establishment of a joint post located in the Banten Labuan Bay fishermen not far from the location of the tsunami victims, located on Jl. Sudirman Labuan Banten. The objectives and programs are 1) All volunteers are obliged to ease the burden on the tsunami victims, all volunteers make contributions in the form of funds; 2) All volunteers must provide motivation to victims; 3) All volunteers must provide therapeutic healing; 4) All volunteers provide good and accurate information. With the implementation of this empowerment, the tsunami victims were greatly helped by the participation of volunteers in helping tsunami victims in the fishing village of Labuan Bay, Banten.
\end{abstract}

Keywords: Tsunami, Community Empowerment, Labuan Banten Bay

\section{Pendahuluan}

Tsunami yang terjadi di Selat Sunda yang berlokasi di Kampung Nelayan Teluk Labuan Kabupaten Pandeglang Banten. Berada sekitar $31 \mathrm{~km}$ dari Kabupaten Pandeglang, 171 km dari Kota jakarta.Terjadi pada tanggal 12 Desember 2018, tsunami yang dilokasi tersebut menjadi bencana nasional karena banyak terjadi kerugian yang menimpanya, kerugian tersebut seperti Rumah, Pasar, Pertokoan, Hotel, cottage, Vila, Sarana umum, sekolah serta banyak korban jiwa, Maka ditetapkan menjadi bencana nasional efisien. ${ }^{1}$

\footnotetext{
1Badan Nasional Penanggulangan Bencana ( BNPB) melalui Kepala Pusat Data, Informasi dan Hubungan Masyarakat
}

Pemberdayaan Masyarakat Korban Tsunami Selat Sunda Kampung Nelayan

Teluk Labuan Banten

Sutarman, Yuyun Yuniarsih, Maria Grace Herlina 
Tsunami yang meliputi korban di 5 kabupaten, yaitu Kabupaten Serang, Kabupaten Pandeglang, Kabupaten Lampung Selatan, Kabupaten Pesawaran, dan Kabupaten Tanggamus. Dari beberapa kabupaten yang dilanda bencana tsunami tersebut yaitu, daerah yang paling parah terdampak tsunami adalah Kabupaten Pandeglang.

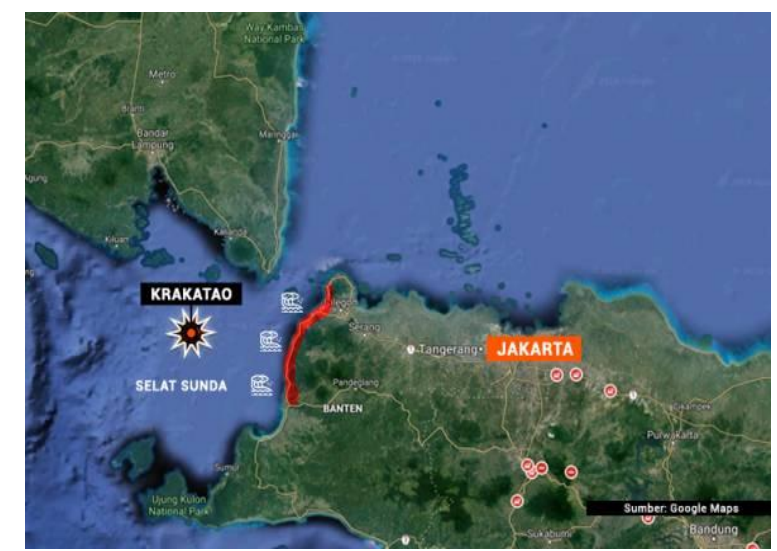

Gambar 1. Peta Tsunami Selat Sunda Sumber Google Map

(Sumber: Dokumentasi, 2019)

Badan Nasional Penanggulangan Bencana (BNPB) melalui Kepala Pusat Data, Informasi dan Hubungan Masyarakat mencatat, hingga tanggal, 25 Desember 2018, jumlah korban meninggal dunia akibat tsunami Banten. Kabupaten Pandeglang 290 orang, Kabupaten Lampung Selatan 108 orang, Kabupaten Serang 29 orang, Kabupaten Pesawaran 1 Orang, Kabupaten Tanggamus 1 orang, Selain korban meninggal, korban luka -luka 1.485 orang, 154 orang hilang, 16.802 orang yang mengungsi di sejumlah daerah dan masih mungkin bertambah seiring dengan proses evakuasi yang masih terus dilakukan baik oleh pemerintah maupun oleh sukarelawan dari berbagai daerah dan berbagai organisasi. Adapun kerusakan fasilitas lainnya sebanyak 882 unit rumah rusak, 73 penginapan berupa hotel dan vila rusak, dan 60 warung rusak, 434 perahu kapal rusak, 24 kendaraan roda 2 rusak, 41 kendaraan roda 4 rusak, 1 dermaga rusak, dan 1 shelter rusak. Oleh karena 
itu pemerintah daerah menetapkan status tanggap darurat bencana di Kabupaten Pandeglang adalah 14 hari, yaitu 22 Desember 2018 hingga 4 Januari 2019. Sedangkan status tanggap darurat bencana di Kabupaten Lampung Selatan adalah 7 hari, terhitung 23 hingga 29 Desember 2019.

\section{Metode}

Pada pelaksanaanya dalam pengabdian pada masyarakat yaitu berupa persiapan pembentukan posko bersama yang berlokasi dikampung nelayan teluk labuan Banten tidak jauh dari lokasi korban tsunami, yang terletak di jl.Sudirman Labuan Banten. Adapun Tim kerjasama yaitu, PDRI yang wakili oleh Yuni dan Sutarman, Tim SR Nyimas Nining, Lina dan Alwi, Tim BFW Juardi dan Nina Tim SR Nyimas Nining, Lina dan Alwi, Tim BFW Juardi dan Nina. $^{2}$
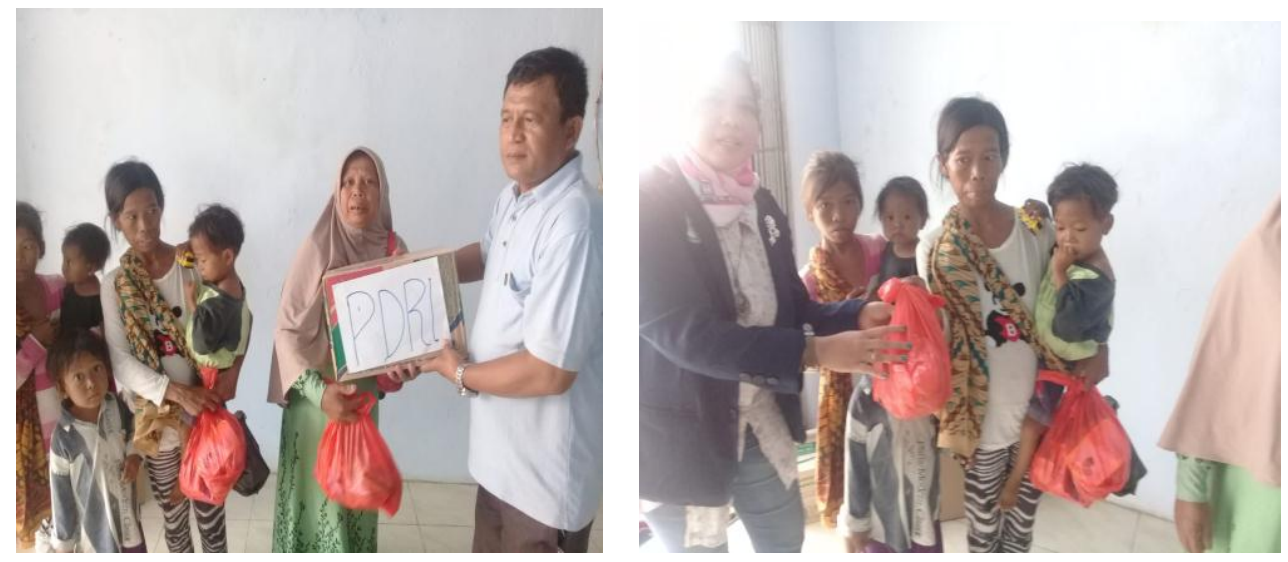

Gambar 2. Penyerahan Bantuan oleh Bendahara PDRI Kepada Masyarakat Korban Tsunami Kampung Nelayan Teluk Labuan Banten

(Sumber: Dokumentasi, 2019)

Kesepakatan dari semua pengurus tim bersama relawan dari berbagai komponen dan berbagai daerah membuahkan hasil kesepakatan yaitu

2Wawancara dengan Tim Yayasan Syekh Ali Jaya yaitu Arif, Tim Yayasan Syekh Ali Jaya yaitu Arif, 2019

Pemberdayaan Masyarakat Korban Tsunami Selat Sunda Kampung Nelayan 
kepedulian pada sesama yang tertimpa bencana tsunami selat sunda. Adapun tujuan dan program seperti berikut dibawah ini :

1) Seluruh relawan berkewajiban meringankan beban yang menimpanya Seluruh relawan memberikan konstribusi berupa dana

2) Seluruh Relawan harus memberikan motivasi

3) Seluruh relawan harus memberikan teraphy healing

4) Seluruh realawan memberikan informasi yang baik dan akurat

Wilayah pesisir pantai di kampung Nelayan Teluk Labuan Banten Banten. Adapun bantuan yang sudah dipersiapkan untuk didistribusi di wilayah pesisir pantai dikampung Nelayan Teluk Labuan Banten berupa sembako, mie instan, air mineral, baju layak pakai, pakaian anak, popok, dan lain sebagainya adapun pendistribusian bantuan tersebut, langsung disampaikan oleh personil tim dan oleh petugas yang ditunjuk sebagai petugas posko. Tim bekerjasama dengan para timcukup solid dan dapat memastikan bantuan sampai ke pihak yang membutuhkan.

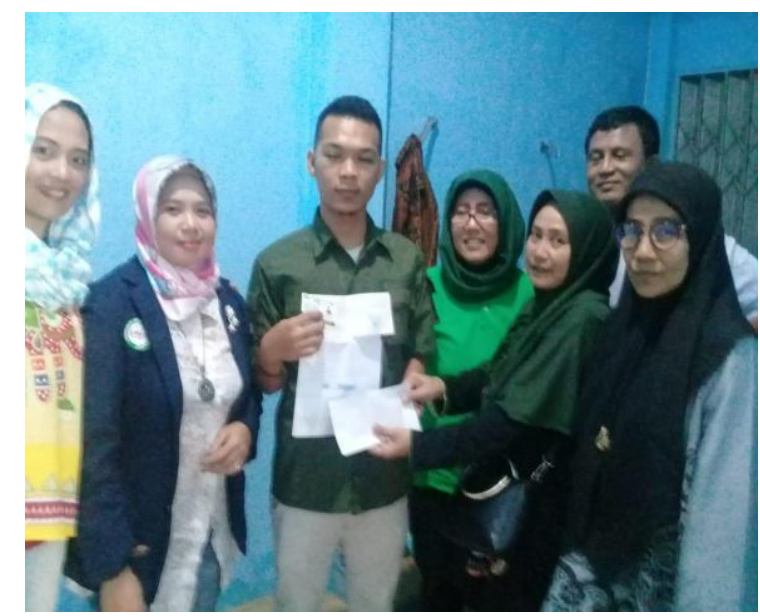

\section{Gambar 3. Penyerahan bantuan Dana dari "SR" kepada masyarakat korban Tsunami dikampung Nelayan Teluk Labuan Banten} (Sumber: Dokumentasi, 2019)

Harapannya dan turut berduka pasca terjadinya bencana tsunami yang menimpa pesisir pantai dikampung Nelayan Teluk Labuan Banten, yang

Pemberdayaan Masyarakat Korban Tsunami Selat Sunda Kampung Nelayan 
termasuk daerah yang berdampaknya parah. Memahami betapa banyak keperluan yang mendesak serta kebutuhkan pada masyarakat yang terkena dampak bencana tsunami. Mengirimkan bantuan dalam tanggap darurat dengan harapan masyarakat yang terdampak bencana tsunami bisa terbantu dan dapat kembali beraktivitas seperti biasa. Adapun lokasi yang sulit dijangkau oleh tim relawan dan hanya bisa dilakukan oleh pihak Dinas Sosial dan oleh aparat yang cukup memadai peralatannya dan yang mengetahui titik-titik dimana masyarakat yang terdampak bencana tsunami berkumpul, serta distribusi barang tsunami berkumpul, serta distribusi barang bantuan sampai kepada penerimanya.

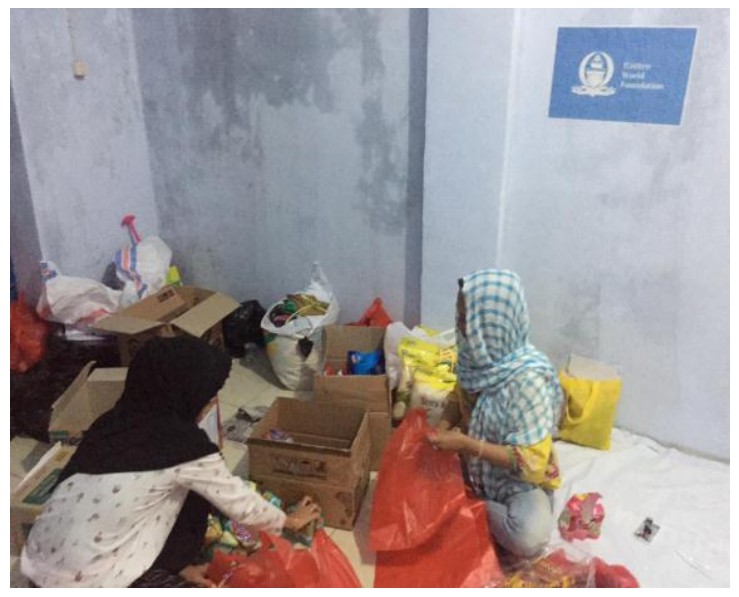

Gambar 4. Logistik Bantuan Sembako siap didistribusikan oleh Petugas Posko Bersama (Sumber: Dokumentasi, 2019)

\section{Hasil dan Diskusi}

Peringatan dini tsunami yang dimiliki oleh BMKG saat ini hanya ada untuk tsunami yang disebabkan gempa bumi tektonik, Sedangkan tsunami yang melanda Selat Sunda yang diakibat vulkanik belum terdeteksi secara rinci, sehingga ketika ada aktivitas vulkanik di Gunung Anak Kraktau selat sunda, sistem peringatan dini tsunami belem bisa memproses data secara otomatis keadaan aktivitas vulkanik sehingga tidak bisa memberikan peringatan (warning) berkaitan dengan tsunami Selat Sunda.

Pemberdayaan Masyarakat Korban Tsunami Selat Sunda Kampung Nelayan 


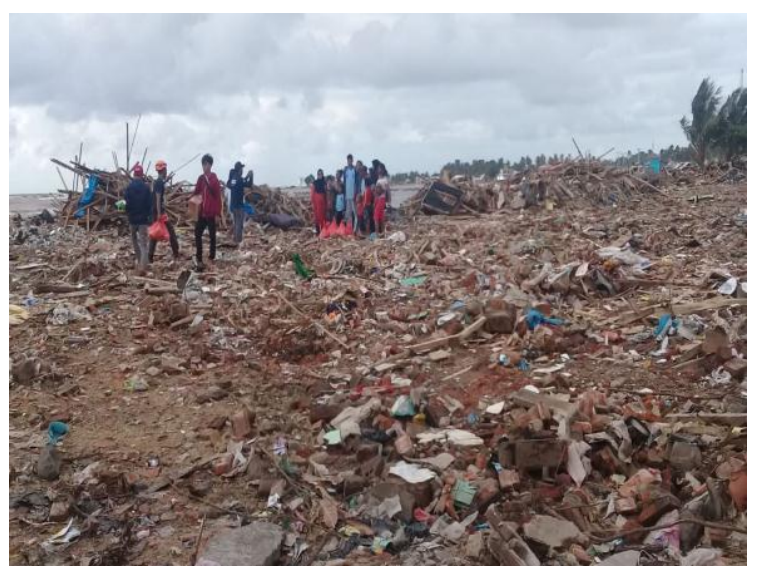

Gambar 5. Kunjungan Pengabdian Masyarakat korban Tsunami dikampung Nelayan Teluk Labuan Banten (Sumber: Dokumentasi, 2019)

Badan Meteorologi Klimatologi dan Geofisika (BMKG) tidak melakukan monitoring seluruh aktivitas Gunung Krakatau dan gunung api lainnya, tetapi yang melakukan monitoring yang lebih detail dan valid yaitu Pusat Vulkanologi dan Mitigasi Bencana Geologi, Badan Geologi, dan Kementrian ESDM. Dari hasil pengecekan dan monitoring tersebut maka ada terindikasi adanya perubahan pada permukaan air laut di beberapa wilayah di Banten seperti di dikampung Nelayan Teluk Labuan, Pantai Jambu, Bulakan, Kec Cinangka, dan Kab Serang dengan ketinggian air mencapai 0.9 m, adapun di Pelabuhan Ciwandan, Kecamatan Ciwandan Banten tercatat dengan ketinggian air mencapai 0.35 m. Bahkan di Kota Agung Kecamatan Kota Agung, Lampung tercatat dengan ketinggian air mencapai $0.36 \mathrm{~m}$. Sedangkan di Pelabuhan Panjang, Bandar Lampung, ketinggian air mencapi $0.28 \mathrm{~m}$. dari pengamatan dan hasil monitoring pada catatan Marigram Tide Gauge Badan Informasi Geospasial (BIG) tersebut, diyakini dan disimpulkan bahwa gelombang air tersebut merupakan gelombang tsunami.

Pemberdayaan Masyarakat Korban Tsunami Selat Sunda Kampung Nelayan 


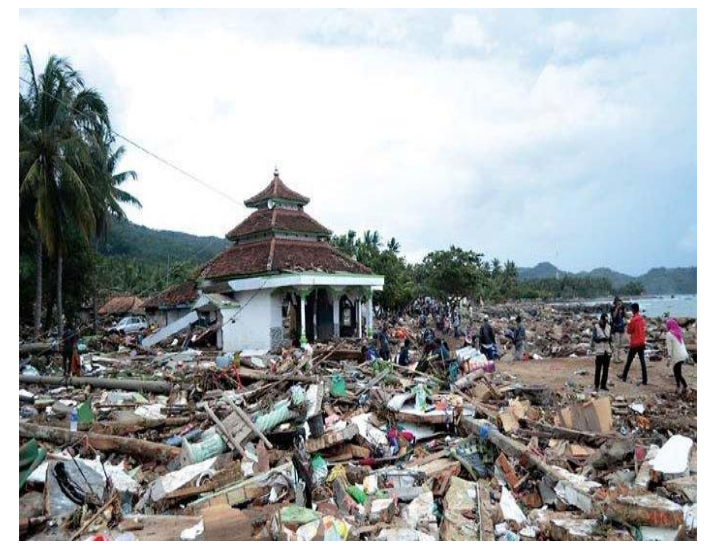

Gambar 6. Kunjungan Pengabdian Masyarakat korban Tsunami Rumah perkampungan hancur di Banten (Sumber: Dokumentasi, 2019)

Inventarisasi Kerugian yang terjadi pada tsunami selat sunda Korban meninggal dunia

1) Kabupaten Pandeglang 290 orang,

2) Kabupaten Lampung Selatan 108 orang,

3) Kabupaten Serang 29 orang,

4) Kabupaten Pesawaran 1 Orang,

5) Kabupaten Tanggamus 1 orang

\section{Korban Luka-luka}

1) Korban luka -luka 1.485 orang,

2) Korban Orang Hilang 154 orang

3) Korban Mengungsi 16.802 orang

\section{Korban kerusakan fasilitas lainnya}

1) Rumah rusak 882 unit

2) Penginapan hotel \& vila 73 unit

3) warung rusak, 60 unit

4) Perahu kapal rusak, 434 unit

5) kendaraan roda 2 rusak 24 unit

6) kendaraan roda 4 rusak, 41 unit

7) Dermaga rusak 1 unit

8) Shelter rusak 1 unit

Pemberdayaan Masyarakat Korban Tsunami Selat Sunda Kampung Nelayan

Teluk Labuan Banten

Sutarman, Yuyun Yuniarsih, Maria Grace Herlina 


\section{Sistem peringatan dini}

Pemerintah Indonesia, telah mengembangkan Sistem Peringatan Dini Tsunami (Indonesian Tsunami Early Warning System). Pada sistem ini yang berpusat pada Badan Meteorologi, Klimatologi, dan Geofisika (BMKG). Yang berpunsi untuk mengirimkan peringatan tsunami dini jika terjadi gempa yang berpotensi tsunami, dan sistem ini memerlukan perbaikan dan penyempurnaan supaya sistem dapat mengeluarkan 3 tahap dalam menginformasikan peringatan, yang sesuai dengan hasil perhitungan Sistem Pendukung dalam Pengambilan Keputusan (Decision Support System).
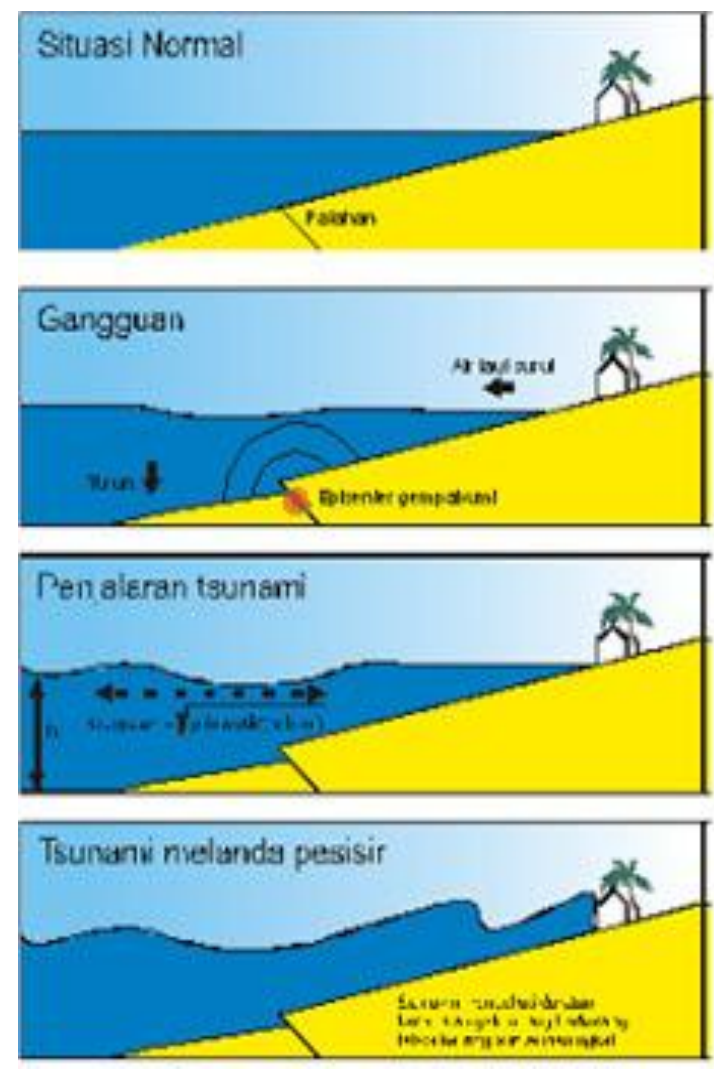

\section{Gambar 7. Ilustrasi Gambar Tsunami}

(Sumber: Dokumentasi, 2019)

Sistem Peringatan Dini dan pengembangannya mesti melibatkan banyak pihak yang terkait, seperti pemerintah pusat, pemerintah daerah,

Pemberdayaan Masyarakat Korban Tsunami Selat Sunda Kampung Nelayan 
lembaga non pemerintah, relawan, sedangkan pihak yang kopenten dan bertanggung jawab untuk mengeluarkan Informasi tsunami peringatan dini dan gempa yaitu Badan Meteorologi, Klimatologi dan Geofisika (BMKG), karena sistem ini dirancang supaya dapat memberikan informasi peringatan dini tsunami dalam jangka waktu lima menit setelah gempa terjadi. Adapun sistem peringatan dini memiliki 4 komponen yaitu ;

1) Pengetahuan mengenai Bahaya dan Resiko,

2) Peramalan, Peringatan, dan Reaksi.

3) Observasi, Monitoring gempa dan permukaan laut

4) Integrasi dan Diseminasi Informasi, Kesiapsiagaan.

\section{Penyebab Terjadinya Tsunami}

Gelombang Tsunami dapat terjadi jika terdapat gangguan yang menyebabkan sejumlah ombak besar air, letusan gunung berapi, gempa bumi, longsor ataupun meteor yang jatuh kepermukaan bumi, akan tetapi dan kerap terjadi 90\% tsunami diakibat gempa bumi bawah laut. Pada jejak sejarah beberapa tsunami diakibatkan oleh gunung meletus, seperyi pada Gunung krakatau ${ }^{3}$. Diakibatkan gerakan vertikal pada kerak bumi yang dapat mengakibatkan dasar air laut naik atau turun secara tiba-tiba, yang mengakibatkan gangguan pada keseimbangan air yang berada dipermukaan laut, maka akan mengakibatkan aliran energi air laut yang ketika sampai di pantai menjadi gelombang air besar yang mengakibatkan terjadinya tsunami. Kecepatan pada gelombang tsunami tergantung pada kedalaman laut yang mana gelombang akan terjadi, apabila kecepatannya mencapai ratusan kilometer per jam, apabila tsunami mencapai pantai, kecepatannya akan berkurang sekitar $50 \mathrm{~km} / \mathrm{jam}$ serta energi gelombangnya akan merusak

${ }^{3}$ Kenneally, Christine. "Surviving the Tsunami". Slate. link, Lambourne, Helen (March 27 2005). "Tsunami: Anatomy of a disaster". BBC News. link, 2004.

Pemberdayaan Masyarakat Korban Tsunami Selat Sunda Kampung Nelayan 
pesisir pantai yang dilaluinya. Akan terjadi ditengah laut ketinggian gelombang tsunami hanya mencami $1 \mathrm{~cm}$ hingga beberapa meter, akan tetapi pada waktu mencapai pantai tinggi gelombangnya akan mencapai puluhan meter karena terjadi penumpukan gelombang air besar dan pada saat mencapai pantai tsunami akan menerjang masuk daratan dari garis pesisir pantai dengan jangkauan mencapai beberapa kilometer.

Gerakan vertikal dapat terjadi pada patahan bumi yang disebut sesar, gempa bumi juga banyak terjadi pada lempeng samudera menuju kebawah lempeng benua. Akan terjadi Tanah longsor di dasar laut serta tumpahan gunung api juga dapat mengakibatkan gangguan gelombang air laut yang dapat menghasilkan tsunami pula. Gempa yang menyebabkan gerakan Vertikal pada lapisan bumi mengakibakan dasar laut naik dan turun secara tiba-tiba ${ }^{4}$., sehingga keseimbangan gelombang air laut yang berada dipermukaan menjadi terganggu dan menimbulkan gelombang besar disebut tsunami, begitupun dengan benda kosmis atau meteor yang jatuh dari atas langit dan apabila ukuran meteor besar maka akan terjadi tsunami besar mencapai ketinggian ratusan meter. Beberapa Gempa yang menyebabkan terjadinya tsunami seperti:

1) Gempa bumi yang berpusat di tengah laut dengan kedangkalan 0-30 km.

2) Gempa bumi dengan kekuatan 6,5 Skala Richter

3) Gempa bumi dengan pola sesar naik ataupun sesar turun

\section{Sistematika Cara Kerja}

Sistematika dari Sistem Peringatan Dini Tsunami adalah merupakan rangkaian sistem kerja yang tidak sederhana karena melibatkan banyak pihak secara terkait secara nasional, regional, daerah lokal pada Masyarakat tersebut. Maka apabila terjadi tsunami atau Gempa, maka akan dicatat secara

${ }^{4}$ The NOAA's page on the 2004 Indian Ocean earthquake and tsunami, Vulkanologi da Mitigasi Bencana Geologi, Badan Geologi, dan Kementrian ESDM, 2004 
otomatis oleh alat Seismograf (pencatat gempa). ${ }^{5}$ Yang mana informasi gempa, menyangut kekuatan gempa, lokasi gempa, waktu kejadian gempa, yang dikirimkan melalui satelit ke BMKG pusat, dan selanjutnya BMKG akan mengeluarkan info gempa yang didistribusikan melalui peralatan teknis secara simultan.

Data gempa dimasukkan dan diolah oleh DSS, untuk mengkalkulasikan gempa tersebut berpotensi tsunami atau tidak, perhitungan dilakukan mellui pemodelan terlebih dahulu kemudian BMKG mengeluarkan informasi peringatan tsunami, data gempa akan diintegrasikan dengan data sistem peringatan dini lainnya seperti (Gps, Buoy, Obu, Tide Gauge) yang berfungsi untuk memberikan konfirmasi dan informasi gelombang tsunami sudah terjadi, Informasi diteruskan oleh BMKG dalam menyampaikan informasi peringatan tsunami melalui beberapa rangkaian perantara, yang meliputi media Pemerintah dan Media lokal lainnya, dan akan meneruskan informasi peringatan kepada masyarakat banyak. BMKG juga berfungsi untuk menyampaikan info peringatan tsunami dini melalui SMS, Facsimile, Telepon, Email, RRadio yang mempunyai fasilitas Data System, serta melalui Website BMKG.

\section{Simpulan}

Pembahasan diatas maka disimpulkan bahwa Tsunami merupakan serangkaian gelombang laut yang merambat dengan kecepatan hingga 900 km per jam, yang diakibatkan oleh gempa bumi yang terjadi di dasar laut. Akan terjadi gangguan yang disebabkan perpindahan sejumlah besar gelombang air, seperti letusan gunung api, gempa bumi, longsor maupun

${ }^{5}$ Iwan, W.D., editor, 2006, Summary report of the Great Sumatra Earthquakes and Indian Ocean tsunamis of 26 December 2004 and 28 March 2005: Earthquake Engineering Research Institute, EERI Publication \#2006-06, 11 chapters, 100 page summary, plus CD-ROM with complete text and supplementary photographs, EERI Report 2006-06. [www.eeri.org] ISBN 1932884-19-X 
meteor yang jatuh ke bumi. Sistem peringatan dini adalah suatu system atau alat yang digunakan oleh pemerinta dalam hal ini Badan Meteorologi Klimatologi dan geofisika memberikan informasi tetang bahaya tsunami dan terjadi tsunami, untuk mengirimkan peringatan tsunami kepada masyarakat sekitar jika terjadi gempa yang berpotensi mengakibatkan tsunami.

Harapannya dan turut berduka pasca terjadinya bencana tsunami yang menimpa pesisir pantai dikampung Nelayan Teluk Labuan Banten, yang termasuk daerah yang berdampaknya parah. Memahami betapa banyak keperluan yang mendesak serta kebutuhkan pada masyarakat yang terkena dampak bencana tsunami. Mengirimkan bantuan dalam tanggap darurat dengan harapan masyarakat yang terdampak bencana tsunami bisa terbantu dan dapat kembali beraktivitas seperti biasa.

\section{Daftar Referensi}

Badan Nasional Penanggulangan Bencana (BNPB) melalui Kepala Pusat Data, Informasi dan Hubungan Masyarakat

Dudley, Walter C. \& Lee, Min (1988: 1st edition) Tsunami! ISBN 0-8248-11259 link

Iwan, W.D., editor, 2006, Summary report of the Great Sumatra Earthquakes and Indian Ocean tsunamis of 26 December 2004 and 28 March 2005: Earthquake Engineering Research Institute, EERI Publication \#200606, 11 chapters, 100 page summary, plus CD-ROM with complete text and supplementary photographs, EERI Report 2006-06. [www.eeri.org] ISBN 1-932884-19-X

Kenneally, Christine (December 30 2004). "Surviving the Tsunami". Slate. link

Lambourne, Helen (March 27 2005). "Tsunami: Anatomy of a disaster". BBC News. link

Macey, Richard (January 1 2005). "The Big Bang that Triggered A Tragedy", The Sydney Morning Herald, p 11 - quoting Dr Mark Leonard, seismologist at Geoscience Australia.

The NOAA's Page On The 2004 Indian Ocean Earthquake And Tsunami.

Vulkanologi dan Mitigasi Bencana Geologi, Badan Geologi, dan Kementrian ESDM. 